\title{
The concentration of kynurenine in rat model of asthma
}

\section{Iwona Kucharewicz ${ }^{1}$, Irena Kasacka ${ }^{2}$, Dariusz Pawlak ${ }^{3}$, Anna Tankiewicz-Kwedlo ${ }^{4}$, Barbara Mroczko ${ }^{5}$, Wlodzimierz Buczko ${ }^{4}$, Anna Bodzenta-Lukaszyk ${ }^{1}$}

\author{
${ }^{1}$ Department of Allergology and Internal Medicine, Medical University of Bialystok, Poland \\ ${ }^{2}$ Department of Histology and Embriology, Medical University of Bialystok, Poland \\ ${ }^{3}$ Department of Monitored Pharmacotherapy, Medical University of Bialystok, Poland \\ ${ }^{4}$ Department of Pharmacodynamics, Medical University of Bialystok, Poland \\ ${ }^{5}$ Department of Biochemical Diagnostics Medical University of Bialystok, Poland
}

\begin{abstract}
Asthma is a chronic inflammatory disease that involves the immune system activation. Evidence is accumulating about the role of kynurenine pathway in the immune system regulation. The kynurenine pathway includes several metabolites of tryptophan, among others kynurenine (KYN). To study the immunological system regulation in asthma a simple and sensitive models of asthma are required. In the present study we induced rat model of asthma using ovalbumin (OVA) sensitization followed by challenge with OVA. The development of asthma has been confirmed by plasma total IgE measurement and the histological examination. The concentration of KYN has been determined in plasma, lungs and liver by highperformance liquid chromatography (HPLC). In OVA sensitized rats the concentration of total IgE was statistically significantly increased as compared to VEH sensitized control groups (437.6 $\pm 97.7 \mathrm{kU} / \mathrm{l}$ vs $159.2 \pm 22.7 \mathrm{kU} / \mathrm{l}$, respectively; p< 0.01). In asthmatic animals, the number of eosinophils, neutrophils and mast cells increased considerably, and epithelial lesion and the increase in airway epithelium goblet cells and edema of bronchial mucosa were present. We did not observe any significant changes in the concentration of KYN in plasma, lungs or liver between studied groups. In conclusion, the concentration of KYN remains unchanged in asthmatic animals as compared to control groups. Further studies using rat model of asthma are warranted to establish the role of kynurenine pathway regulation in asthma.
\end{abstract}

Key words: Kynurenine pathway - Asthma - Rat

\section{Introduction}

During last decade's prevalence of asthma increased gradually. An intriguing finding is that the link between atopic sensitization and asthma symptoms increased with economic development [1]. Asthma is a chronic inflammatory disorder which involves many inflammatory cells and mediators [2,3]. The current treatment of asthma is based on anti-inflammatory drugs, mainly corticosteroids that intended to reduce inflammatory process. However, corticosteroids are very efficient in inhibiting airway inflammation; they exert very mild effect on structural changes in the air-

Correspondence: I. Kucharewicz, Dept. of Allergology and Internal Medicine, Medical University of Bialystok, Sklodowska-Curie Street 24A, 15-276 Bialystok, Poland; tel.: (+4885) 7468373, fax.: (+4885) 7468601, e-mail: ikuchar@poczta.onet.pl ways $[4,5]$. The complexity of the natural course of the disease prompts investigators to look for more effective therapy.

Evidence is accumulating about the role of the kynurenine pathway in the immune system regulation. Tryptophan (TRP), an essential amino acid, is metabolized mainly though kynurenine pathway by two different rate-limiting enzymes: tryptophan 2,3- dioxygenase (TDO), located primarily in the liver, and indoleamine 2,3- dioxygenase (IDO) found in many immune system cells (eg. dendritic cells, monocytes, macrophages) and tissues [6,7]. Tryptophan catabolism leads to kynurenine (KYN) generation which has been reported to possess important immunoregulatory properties in vitro [8].

To study the immunological system regulation in asthma a simple and sensitive models of asthma are required. Rat, in comparison with other animals, demonstrates many features of airway allergy and 
allergic asthma that are similar to human [9]. The aim of the present study was to establish ovalbumin (OVA)-sensitized rat model of asthma and to evaluate the concentration of KYN in asthmatic animals.

\section{Materials and methods}

Animals. 24 male Wistar rats (160-180 g) were housed in a room with a $12 \mathrm{~h} \mathrm{light/dark} \mathrm{cycle,} \mathrm{in} \mathrm{group} \mathrm{cages} \mathrm{as} \mathrm{appropriate,} \mathrm{given}$ tap water and fed a standard rat chow.

Induction of experimental asthma in rats. Experimental asthma was induced by ovalbumin (OVA) sensitization followed by OVA challenge $(n=6)$.

OVA sensitization. Sensitization was performed by intraperitoneal injection of $200 \mu \mathrm{g} / \mathrm{ml}$ of OVA (Grade V; Sigma Chemical Co, St. Louis, MO) (1 ml of OVA- $\mathrm{Al}(\mathrm{OH})_{3}$ suspension) on days $1,2,3$, and 11 of the experiment [10]. OVA was diluted in $400 \mu \mathrm{g} / \mathrm{ml}$ in saline and precipitated at $1: 1$ ratio with $\mathrm{Al}(\mathrm{OH})_{3}(13 \mathrm{mg} / \mathrm{ml}$, Aluminum hydroxide gel, Sigma Chemical Co, St. Louis, MO). On the first day a foot pad injection of heat-killed Bordetella pertussis ( $10^{10}$ in $50 \mu \mathrm{l}$ saline) (Sigma Chemical Co, St. Louis, MO) was given as an adjuvant. Control groups received saline- $\mathrm{Al}(\mathrm{OH}) 3$ (VEH) immunization and foot pad injection of Bordetella pertussis.

OVA challenge. Asthma was induced by allergen challenge. Starting from day 19 and continuing for 7 consecutive days, the allergen challenge was done with 1\% OVA in saline [10]. This was accomplished by placing rats in a plexiglas chamber $50 \times 30 \mathrm{~cm}$ connected to a nebulizer (pneumatic nebulizer Voyage, Poland) generating an aerosol mist. Control groups received saline (VEH) in the same manner.

Control groups constituted: saline sensitized rats challenged with VEH $(\mathrm{VEH} / \mathrm{VEH})(\mathrm{n}=6)$, saline sensitized rats challenged with OVA (VEH/OVA) $(n=6)$, and OVA-sensitized rats challenged with saline $(\mathrm{OVA} / \mathrm{VEH})(\mathrm{n}=6)$.

Blood withdrawing and total IgE measurement. 24 hours after the last challenge, rats were anaesthetized with pentobarbital (40 $\mathrm{mg} / \mathrm{kg}$; ip) and blood was collected from the heart. Briefly, citrate anticoagulated blood samples were immediately centrifuged at $3000 \mathrm{rpm}$ for $20 \mathrm{~min}$ at $4 \mathrm{C}$ and supernatants were aliquoted and were frozen at $-80^{\circ} \mathrm{C}$ until assay. Plasma total $\mathrm{IgE}$ measurement was performed using rat IgE Elisa quantification kit (Bethyl Laboratories.Inc).

Tissue sampling. After blood withdrawing the lungs and the liver were removed, sliced (60-100 mg of weight) and rapidly frozen on ice. Samples were homogenized $(100 \mathrm{mg} / 0.5 \mathrm{ml})$ in ice-cold $20 \%$ trichloroacetic acid. Homogenates were centrifuged at $14000 \times \mathrm{g}$ for $30 \mathrm{~min}$ and sonificated.

The determination of plasma, lung and liver KYN. The concentration of kynurenine was determined by high-performance liquid chromatography (HPLC) according to Holmes [11]. The reversedphase HPLC system consisted of a Waters Spherisorb S3 ODS2 $150 \times 2.1 \mathrm{~mm}$ column (USA), HP 1050 series pump (Germany), Rheodyne injection valve fitted with a sample loop $(5 \mu l)$. The column effluent was monitored using a UV detector HP 1050 (Germany) - $365 \mathrm{~nm}$. The output of the detector was connected to a single instrument LC-2D ChemStation (Germany). The mobile phase consisted of $0.1 \mathrm{M}$ acetic acid, $0.1 \mathrm{M}$ ammonium acetate ( $\mathrm{pH} 4.65)$ containing $1.8 \%$ of acetonitrile and was pumped at a flow-rate of $0.25 \mathrm{ml} / \mathrm{min}$. Chromatography was carried out at $25^{\circ} \mathrm{C}$.
Method of experimental material collection and fixation. After blood collection, the animals were sacrificed by cutting the heart. Following a thoracotomy, the lungs were collected in whole. Immediately after the preparation of the collected organ, Bouin's fluid was administered by syringe into the trachea to smooth the pulmonary pleura in the right lung. Following the ligation of trachea, the lung was fixed in Bouin's fluid for $24 \mathrm{~h}$ in temperature of $+4^{\circ} \mathrm{C}$. Then, following lobotomy from the circumference to the hilus, the anterior part of the superior pulmonary lobe, directly above the tracheal bifurcation, were routinely placed in paraffin blocks and then sectioned by a Leica 2025 rotating microtome.

Applied routine histological staining methods. The obtained $4-\mu \mathrm{m}$ sections were stained with haematoxylin and eosin $(\mathrm{H}+\mathrm{E})$ for general histological evaluation and by May-Grunwald solution at $35^{\circ} \mathrm{C}$ for 20 minutes, than stained in diluted Giemza solution in $35^{\circ} \mathrm{C}$ for 40 minutes. To study goblet cells in the bronchial epithelium PAS staining method was used.

Histological evaluation was performed by experienced histologist in a blinded fashion. The obtained results of immunohistochemical staining were submitted for evaluation in an Olympus Bx50 microscope. Mast cells and inflow elements (eosinophils, neutrophils) were searched for along with their topography.

Ethical issues. Procedures involving the animals and their care were conducted in accordance with the institutional guidelines that are in compliance with national and international laws and Guidelines for the Use of Animals in Biomedical Research (Thromb Haemost $1987 ; 58: 1078-84)$. The study was approved by the local Ethics Committee (21/2006).

Statistical analysis. The values are expressed as the mean $\pm \mathrm{SD}$, $\mathrm{n}$ - represents the number of experiments. Muliple groups comparisons were performed by one-way of variance, and significant intergroup's differences were assessed by Tukey-Kramer test. The $p$ values less than 0.05 were considered significant.

\section{Results}

Plasma total IgE was statistically significant higher in OVA sensitized rats as compared to VEH sensitized control groups (437.6 $\pm 97.7 \mathrm{kU} / 1$ vs $159.2 \pm 22.7 \mathrm{kU} / 1$, respectively; $\mathrm{p}<0.01)$.

Development of asthma has been also confirmed by histological examination. The analysis of microscopic sections showed significant changes in number and distribution of inflammatory cells in studied groups of animals. In light microscopy based on general analysis of lung section there were no significant differences in number and localization of mast cells and migrated cells in control groups (Fig. 1A (VEH/VEH), Fig. 1B (VEH/OVA), and Fig. 1C (OVA/VEH)). In these animals single mast cells were localized mainly beside blood vessels and in interalveolar septa and only single neutrophils were observed. In lungs from asthmatic animals (OVA/OVA) the number of mast cells increased considerably and they had much more regular distribution (Fig. 2). The highest accumulation of mast cells was present around bronchia, nearby blood vessels, and in interalveolar septa. Mast cells in this group were bigger in size and had much stronger intensity of staining in comparison with control 

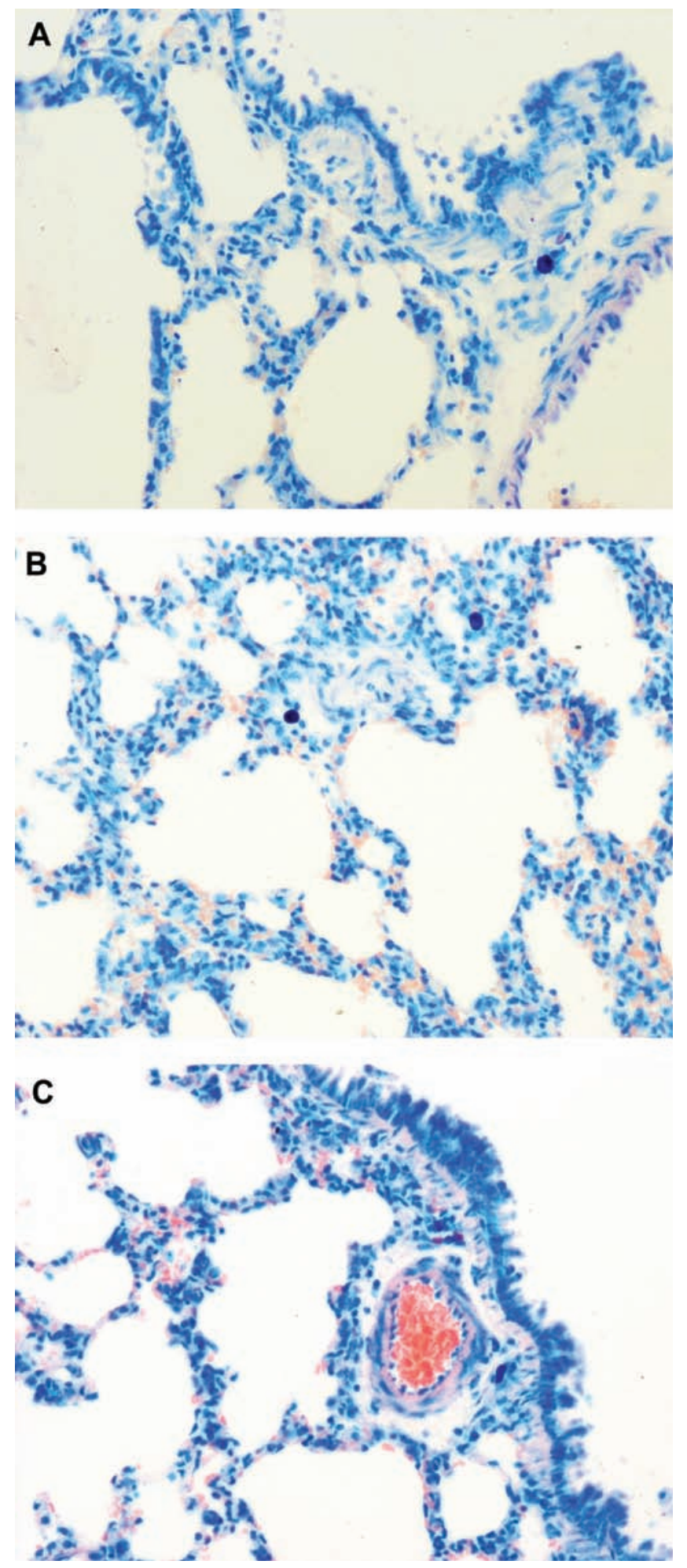

Fig.1 Lung of control animals (A.VEH/VEH, B.VEH/OVA, C. OVA/VEH), only single mast cells were visible. May-Grunwald and Giemza stain (magnification $\times 200$ ).

groups. The development of asthma caused also marked mobilization of migrated cells, especially eosinophils and neutrophils. Additionally in asthmatic subjects epithelial lesion of bronchi and bronchioles

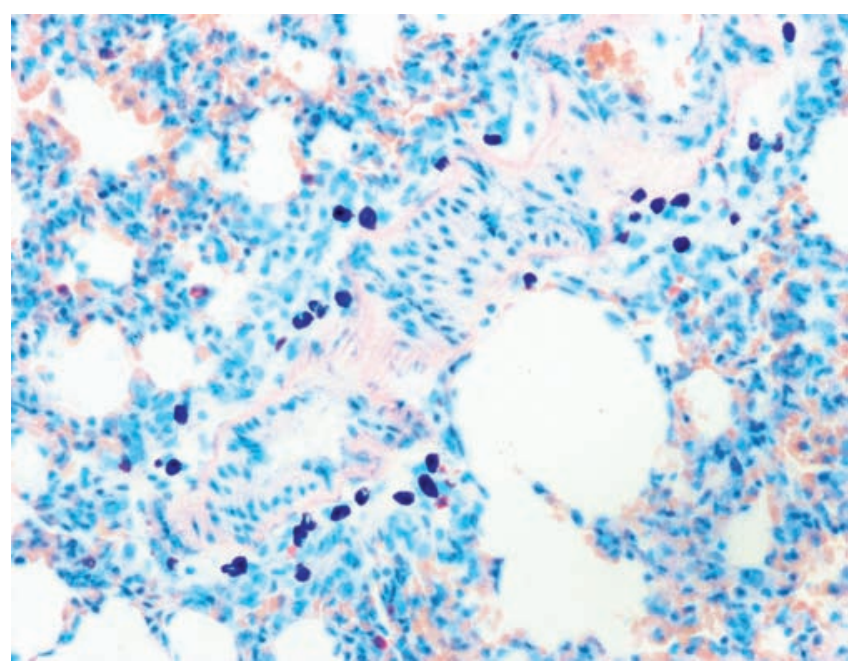

Fig. 2. Lung specimen of asthmatic animals, numerous mast cells concentrated around bronchia, blood vessels, and interalveolar septa. May-Grunwald and Giemza stain (magnification $\times 200$ ).

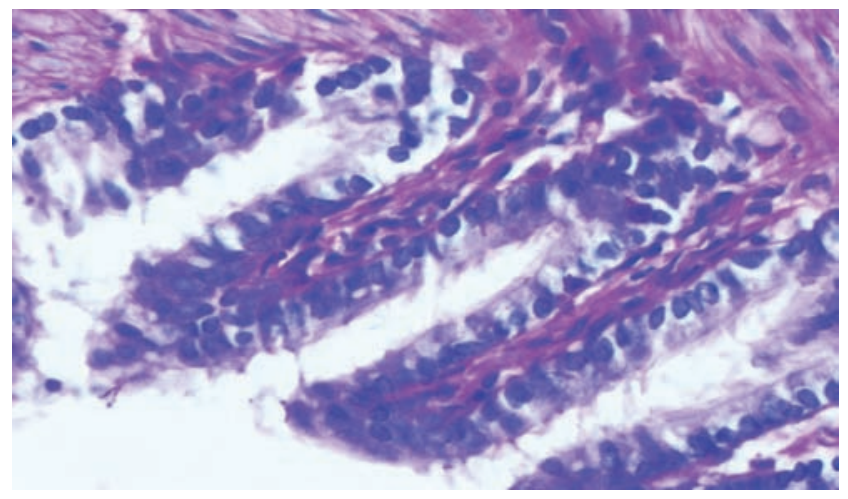

Fig. 3. Fragment of a lung from control group (VEH/OVA). PAS stain (magnification $\times 400$ ).

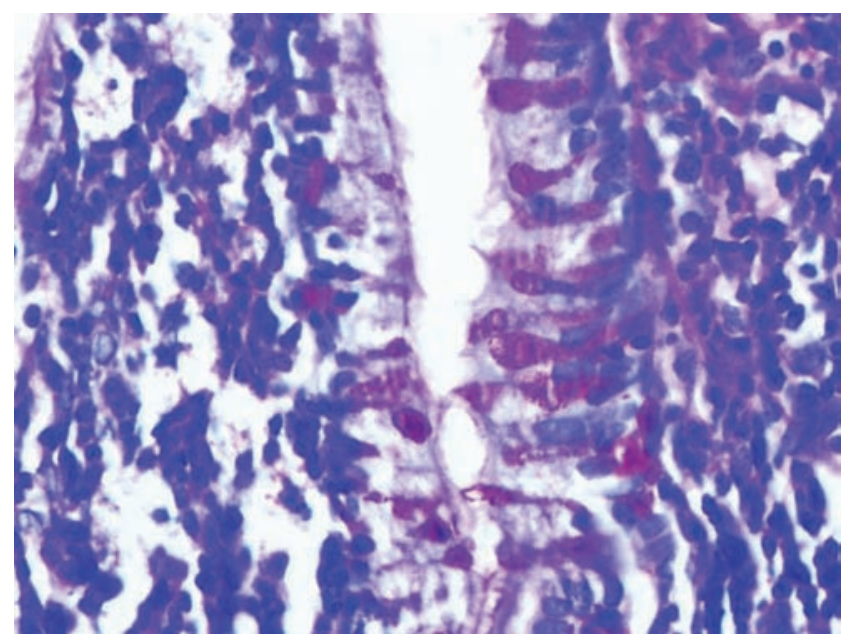

Fig. 4. Fragment of a lung from rat with asthma (OVA/OVA), numerous goblet cells in the epithelium of bronchus. PAS stain (magnification $\times 400)$. 
were observed. In certain cells changes in the shape and epithelium shedding were present. The studied animals had a different number of goblet cells. Only a very few goblet cells were present in control groups (Fig. 3). In contrast, in asthmatic subjects the increase in airway epithelium goblet cells (Fig. 4) and also edema of bronchial mucosa occurred.

The concentration of KYN in the plasma was $1.7 \pm$ $0.3 \mu \mathrm{M}, 1.9 \pm 0.4 \mu \mathrm{M}, 1.6 \pm 0.4 \mu \mathrm{M}$, and $1.7 \pm 0.5 \mu \mathrm{M}$ for VEH/VEH, VEH/OVA, OVA/VEH, and OVA/OVA, respectively. It remains also not statistically different between studied groups in the lungs $(3.1 \pm$ $0.6 \mathrm{nmol} / \mathrm{g} 2.7 \pm 0.7 \mathrm{nmol} / \mathrm{g}, 2.9 \pm 0.6 \mathrm{nmol} / \mathrm{g}$, and 2.3 $\pm 0.8 \mathrm{nmol} / \mathrm{g}$ for $\mathrm{VEH} / \mathrm{VEH}, \mathrm{VEH} / \mathrm{OVA}, \mathrm{OVA} / \mathrm{VEH}$, and OVA/OVA, respectively) and in the liver ( $2.9 \pm 0.3$ $\mathrm{nmol} / \mathrm{g}, 3.5 \pm 0.7 \mathrm{nmol} / \mathrm{g}, 2.9 \pm 0.4 \mathrm{nmol} / \mathrm{g}$, and $3.0 \pm$ $0.4 \mathrm{nmol} / \mathrm{g}$ for $\mathrm{VEH} / \mathrm{VEH}, \mathrm{VEH} / \mathrm{OVA}, \mathrm{OVA} / \mathrm{VEH}$, and OVA/OVA, respectively).

\section{Discussion}

In the present study the experimental model asthma has been induced by OVA-sensitization followed by challenge with OVA. In OVA sensitized rats plasma IgE has the highest values as compared to VEH sensitized control groups. The increase in total IgE represents development of sensitization against ovalbumin. Additionally, to further confirm the development of experimental asthma, we perform histological examination. In light microscopy of the lung in asthmatic animals (OVA/OVA), the number of eosinophils and neutrophils increased considerably as compared to control groups. In OVA/OVA group definitely also much more mast cells were present. Mast cells were localized around bronchia and nearby blood vessels. They had a different activity which was observed as different intensity of staining. Also epithelial lesion and the increase in airway epithelium goblet cells and edema of bronchial mucosa were present in asthmatic subjects.

Rat, in comparison with other animals, e.g. mice, demonstrates many features of airway allergy and allergic asthma that are similar to human [6]. It is known that rat develop both, immediate and late asthmatic responses after allergen challenge or after nonspecific challenge [12]. In sensitized rat in response to allergen challenge both, CD4+ and $\mathrm{CD} 8+$ cells are activated and they express Th2 cytokines [13]. Nevertheless, rat is a weak bronchoconstrictor and more agonist is necessary to produce the airways narrowing similar to guinea pigs [14]. Therefore rat model of asthma is focused mainly on inflammatory process, which progresses during disease natural course. Thus, rat model of asthma will contribute greatly to our understanding the mechanisms of allergic inflammation underlining asthma. It should also improve trans- lation of basic research on immune system regulation into clinical practice.

There are two theories relating to the role of tryptophan metabolism in immune system regulation: the depletion of tryptophan and the accumulation of tryptophan metabolites [15]. Tryptophan depletion theory is based on the finding that the breakdown of tryptophan dramatically reduced the supply of this most energetically expensive amino acid to synthesize [7]. Kynurenine is the first product of tryptophan metabolism that accumulates after kynurenine pathway activation. In the present study we measure the concentration of kynurenine in rats with experimental asthma. We noticed that the concentration of kynurenine did not differ between studied groups neither in plasma, lungs nor in the liver. Kynurenine has been reported to act as a potent apoptotic agent for activated $\mathrm{T}$ cells resulting in decreased T-cell proliferation $[9,16]$. In patients with bronchial asthma, there is only one available study showing that serum kynurenine was increased [17]. Typically OVA sensitization and challenge leads to Th2 phenotype generation [13], and in turn Th2 cytokines are released, mainly IL-4 and IL13. It is known that both of these cytokines suppress indolamine 2,3 dioxygenase activity [18], which might result in the decrease in kynurenine generation or at least in the unchanged level in asthmatic subjects as compared to control groups. It should also be pointed out that in animal model of asthma together with increasing allergen challenges after allergen sensitization, the tolerance might develop [19]. Therefore the lack of differences in kynurenine concentration observed in the present study should be taken with caution, and the precise mechanisms responsible for the observed results need to be established. Also the involvement of other kynurenine pathway metabolites should be verified.

In conclusion, the concentration of KYN remains unchanged between asthmatic animals and control groups. Further studies using rat model of asthma are warranted to establish the role of the kynurenine pathway regulation in asthma.

\section{References}

[ 1] Weinmayr G, Weiland SK, Bjorksten B et al. Atopic Sensitisation and the International Variation of Asthma Symptom Prevalence in Children. Am J Respir Crit Care Med. 2007; 176:565-74.

[ 2] Djukanović R, Wilson JW, Britten KM et al. Quantitation of mast cells and eosinophils in the bronchial mucosa of symptomatic atopic asthmatics and healthy control subjects using immunohistochemistry. Am Rev Respir Dis. 1990;142:86371.

[3] Kucharewicz I, Kowal K, Buczko W, Bodzenta-Lukaszyk A. The Plasmin system in airway remodeling. Thromb Res. 2003;112:1-7.

[4] Jeffery PK, Godfrey RW, Adelroth E, Nelson F, Rogers A, Johansson SA. Effects of treatment on airway inflammation 
and thickening of basement membrane reticular collagen in asthma. A quantitative light and electron microscopic study. Am Rev Respir Dis. 1992;145:890-99.

[ 5] Johnson PRA, Black JL, Tamm M. Proliferation of asthmatic and non asthmatic smooth muscle cells in culture- effect of formoterol and budesonide. Am J Respir Crit Care Med. 2001;163:A270.

[6] Moffet JR, Namboodiri MA. Tryptophan and immune response. Immunol Cell Biol. 2003:81:247-65

[ 7] Von Bubnoff D, Hanau D, Wenzel J et al. Indoleamine 2,3dioxygenase-expressing antigen-presenting cells and peripheral T-cell tolerance: Another piece to the atopic puzzle? $J$ Allergy Clin Immunol. 2003;112:854-60.

[ 8] Terness P, Bauer TM, Röse L, Dufter C, Watzlik A, Simon H, Opelz G. Inhibition of alleogenic $\mathrm{T}$ cell proliferation by indoleamine 2,3-dioxygenase-expressing dendritic cells: mediation of suppression by tryptophan metabolites. J Exp Med. 2002;196:447-57.

[ 9] Pauluhn J, Mohr U. Experimental approaches to evaluate respiratory allergy in animal models. Exp Toxicol Pathol. 2005;56:203-34.

[10] Shimizu T, Hirano H, Majima Y, Sakakura Y. A mechanism of antigen-induced mucus production in nasal epithelium of sensitized rats. A comparison with lipopolysaccharide-induced mucus production. Am J Respir Crit Care Med. 2000;161; 1648-54.

[11] Holmes EW. Determination of serum Kynurenine and hepatic Tryptophan diooxygenase activity by high liquid chromatography. Anal Biochem. 1988;172:518-25.
[12] Waserman S, Olivenstein R, Renzi P, Xu LJ, Martin JG. The relationship between late asthmatic responses and antigenspecific immunoglobulin. J Allergy Clin Immunol. 1992;90: 661-9.

[13] Martin JG, Tamaoka M. Rat models of asthma and chronic obstructive lung disease. Pulm Pharmacol Ther. 2006;19: 377-85.

[14] Pauluhn J, Mohr U. Experimental approaches to evaluate respiratory allergy in animal models. Exp Toxicol Pathol. 2005; 56:203-34.

[15] Mellor AL, Munn DH. Tryptophan catabolism and T-cell tolerance: immunosupression by starvation? Rev Immunol Today. 1999;20:469-73.

[16] Frumento G, Rotondo R, Tonetti M, Damonte G, Benatti U, Ferrata GB. Tryptophan-derived catabolites are responsible for inhibition of $\mathrm{T}$ and natural killer cell proliferation induced by indoleamine 2,3-dioxygenase. $J$ Exp Med. 2002;196:459-68.

[17] Warraki SE, El-Gammal MY, El-Asmar MF, Wahba N. Serum kynurenine in bronchial asthma and chronic bronchitis. Chest. 1970;57:148-50.

[18] Grohmann U, Orabona C, Fallarino F, Vacca C, Calcinaro F, Falorni A, Candeloro P, Belladonna ML, Bianchi R, Fioretti MC, Puccetti P. CTLA-4 regulates tryptophan catabolism in vivo. Nat Immunol. 2002;3:1097-101.

[19] Zosky GR, Sly PD. Animal models of asthma. Clin Exp Allergy. 2007;37:973-88.

Submitted: 7 July, 2007 Accepted after reviews: 17 January, 2008 